\title{
Stakeholder collaboration: evaluating community-based conservancies in Kenya
}

\author{
Lily Maynard, Susan K. Jacobson and John Kamanga
}

\begin{abstract}
To evaluate and improve the involvement of stakeholders in community-based natural resource management, we developed a stakeholder collaboration index. We compared the stakeholders of five Kenyan conservancies by conducting 10 focus group meetings with conservancy management committees and wildlife game scouts. We used the nominal group technique to identify and rank perceptions of the conservancies' strengths, weaknesses and opportunities, and any threats. The resulting 455 responses were categorized into ecological, institutional or socioeconomic themes of ecosystem management. Collaboration index scores ranged from low (0.33) to high (0.95) collaboration, on a scale of $0-1$, with a mean of 0.61 . Managers and game scouts had varying perceptions of the conservancies but they agreed about major strengths and threats to conservation. The index highlighted shared perspectives between managers and scouts, which could be used as opportunities for increased stakeholder involvement in collaborative management. The stakeholder collaboration index is a potentially useful tool for improving management of environmental conservation programmes.
\end{abstract}

Keywords Collaboration, community-based natural resource management, conservancy, evaluation, Kenya, stakeholder collaboration index, stakeholder participation

\section{Introduction}

Community-based natural resource management is a prevalent approach to conservation in Africa, made complex by the diversity of stakeholders involved and a history of both success and failure (Horwich \& Lyon, 2007; Manfredo, 2008). This management framework emphasizes participation and involves community members, who may otherwise be excluded from decision-making in topdown, government-managed programmes (Berkes, 2004). Stakeholder participation in community management can

LILY MAYNARD (Corresponding author (D) orcid.org/0000-0003-0443-1580) School of Natural Resources and Environment, University of Florida, P.O. Box 110430, Gainesville, Florida 32611-0430, USA. E-mail lilytmaynard@ufl.edu

Susan K. JaCobson Department of Wildlife Ecology and Conservation, University of Florida, Gainesville, Florida, USA

John Kamanga South Rift Association of Landowners, Nairobi, Kenya

Received 1 August 2017. Revision requested 2 October 2017.

Accepted 22 May 2018. First published online 28 February 2019. be developed by recognizing shared interests between community members (Saengsupavanich et al., 2012).

Collaboration among stakeholders can strengthen community-based natural resource management by engaging diverse local participants in community projects (Masozera et al., 2006). Transparent decision-making through stakeholder participation fosters trust, empowerment and equity, and is best practice for conservation programmes (Berkes, 2004; Reed, 2008). Community participation in decision-making improves compliance with regulations and the achievement of programme objectives (Berkes, 2007; Brooks et al., 2012).

To incorporate stakeholder collaboration into organizational processes for ecosystem management (Bonnell \& Koontz, 2007; Saengsupavanich et al., 2012) we created a stakeholder collaboration index to evaluate how collaboration among stakeholders in community-based natural resource management programmes could be more effective. Intensive stakeholder analysis can identify prime areas of consensus by quantifying and highlighting the common ground between stakeholders, which is essential for effective collaboration (Margerum, 2008). Our analysis is an adaptation of the Potential for Conflict Index (Vaske et al., 2010), but instead of focusing on conflict and disparities we emphasize positive interactions and similarities between stakeholders. This adapted index highlights and displays the central tendency, dispersion and distribution of results in bubble graphs for an accessible comparison of stakeholders' views, which can be integrated into conservation management planning (Manfredo et al., 2003; Vaske, 2008).

Evaluation of the major factors affecting communitybased natural resource management programmes, specifically their ecological, institutional and socio-economic components, can focus management efforts on improving programmes and promoting strategic planning and transparency among stakeholders (Meffe, 2002; Margoluis et al., 2009). These three themes encompass the facets of community-based natural resource management programmes that influence their efficacy towards conservation success (Meffe, 2002). We tested these themes as components of conservation management from the perspective of various stakeholders within community conservancies, which consist of land set aside by communities for natural resource and wildlife conservation. Seeking common ground between stakeholders can create a basis for collective buy-in for conservation, to overcome conflicts (Rust, 2017).

Using the index to evaluate the potential for collaboration can determine which activities are prioritized by 
different stakeholders, including an organization's objectives, institutional features and policies. Creating the means for collaboration can lead to more effective decision-making and programme implementation, and resilience to future challenges, with increased capacity for adaptation and innovation (Wondolleck \& Yaffee, 2000; Folke et al., 2005; Keough \& Blahna, 2006).

Applying the stakeholder collaboration index is unique in its emphasis on collaboration rather than conflict. Conflict-centred studies have contrasted perceptions of wildlife management techniques (Manfredo et al., 2003), hunting scenarios and disease management (Vaske et al., 2006), invasive species (Wald et al., 2013), and communitybased natural resource management programmes in developing countries (Larson et al., 2016). Although conflict studies can be relevant (e.g. Wall \& Callister, 1995; Jehn \& Mannix, 2001) and projects focused on resolving environmental management conflicts are beneficial to address natural resource issues (e.g. Konisky \& Beierle, 2000; Mushove \& Vogel, 2005; Thompson et al., 2005; Madden \& McQuinn, 2014), the stakeholder collaboration index can provide the structure to facilitate effective collaborative management. Conflict can occur during the development of collaborative community-based natural resource management programmes (McDougall \& Banjade, 2015), but those with clear organizational structures for partnerships are more likely to succeed (Mburu \& Birner, 2007).

To illustrate the potential value of the stakeholder collaboration index as a framework, we tested the model's ability to highlight areas ripe for implementing collaborative ecosystem management, or the lack thereof, when investigating stakeholders' perspectives within community conservancies. We tested the framework in a case study, using a common evaluation framework to demonstrate its applicability for other environmental management programmes in international settings.

The case study focuses on five conservancies in one region of southern Kenya. Community-based natural resource management projects are widespread in Kenya, with $>150$ conservancies established by communities for conservation and sustainable use of natural resources outside government parks and reserves (Western et al., 2015). These projects are critical for Kenyan wildlife conservation efforts, as $>70 \%$ of wildlife occurs outside government protected areas, of which, $>40 \%$ are protected by community and private conservancies (Western et al., 2009, 2015).

Our objectives were (1) to test the efficacy of the stakeholder collaboration index for identifying areas of compatibility within and between stakeholder groups, to facilitate collaborative conservation management, and (2) to determine similarities in stakeholders' perceptions of programme strengths, weaknesses and opportunities, and any threats, within the Kenyan conservancies in this case study.

\section{Case study}

We examined five of the conservancies in a region of 15 Maasai group ranches in a 950,00o ha area of Kenya's southern Rift Valley: Shompole, Olkiramatian, Loita, Olorgesailie and Empaash Olorenito (Fig. 1). Group ranches comprise land that is shared communally based on pastoralist livestock herding traditions. The region is rich in plant and animal diversity, and contains ecological corridors between Maasai Mara National Reserve and Amboseli National Park (Western et al., 2015).

The five conservancies (each c. 8,000-10,00o ha) serve as grazing refuges for livestock during times of need, such as the dry season, as well as community-regulated preserves for wildlife and natural resources. Olkiramatian and Shompole are well established, with tourist facilities and $>10$ years of operation, whereas the Empaash Olorenito, Loita and Olorgesailie conservancies have been in operation for $<5$ years.

All five conservancies were created internally within the communities, with minimal external advisement from government agencies or NGOs. The five communities created their conservancies as a response to threats of environmental degradation, and to modernize traditional Maasai resource regulations created via elected committees. Two stakeholder groups are integral to the creation, management and operation of a conservancy: a management committee and game scouts. Each conservancy management committee comprises $5-8$ communally elected people who oversee the conservancy. Each committee employs a similar number of local men as game scouts to monitor and enforce the conservation and sustainable-use rules, which are based on Maasai conservation traditions and reinforced by the committee's decisions. These two stakeholder groups have distinct roles in the conservancies and have yet to develop structures for collaborative management linking their viewpoints and activities. Thus, both management committee members (managers) and game scout team members (scouts) were included in this study, as the key stakeholders in this system.

\section{Methods}

\section{Stakeholder group meetings}

During May-August 2014, 10 meetings were conducted in the five Maasai conservancies, using the nominal group technique (Maynard \& Jacobson, 2017). Five of these group meetings were held with conservancy managers and five with scouts, involving 55 participants in total.

Non-random, purposeful sampling guided participant selection. As managers and scouts potentially have distinct perspectives, given their contrasting roles, the two stakeholder groups met separately, to establish a homogeneous 


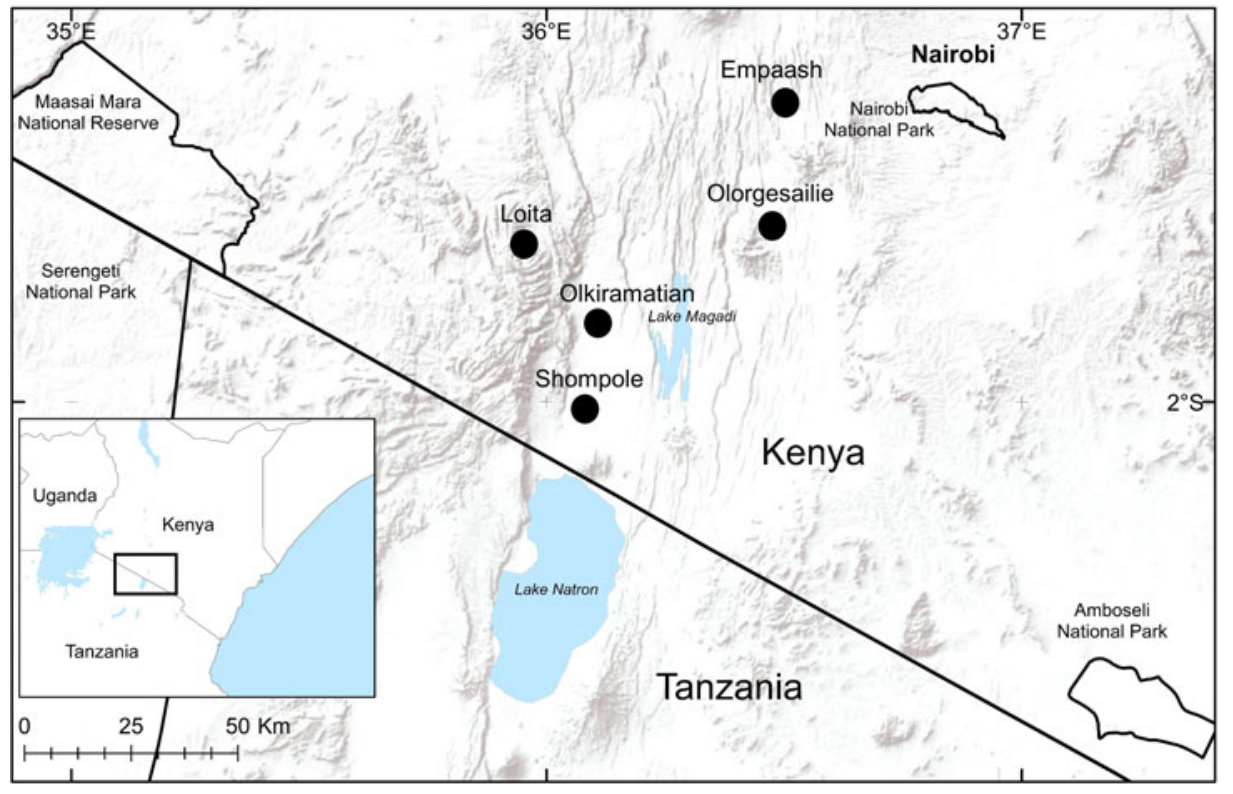

FIG. 1 Location of the five study conservancies in the southern Rift Valley of Kenya: Loita, Olkiramatian, Shompole, Empaash and Olorgesailie. Figure courtesy of Peadar Brehony. and comfortable atmosphere (Tullberg, 2013). Several screening criteria were used: participants must (1) have lived on the group ranch for at least 5 years; (2) be adults $>18$ years old; and (3) not include people from the same household (e.g. husband and wife, siblings). All of the managers and scouts participated in the group meetings.

We used the nominal group technique to record participants' ideas about the conservancies, both qualitatively and quantitatively (Van de Ven \& Delbecq, 1971). This method was selected based on preliminary research in the region and consultation with local community informants. The analyses recorded the perceptions of both current and anticipated positive and negative features of a project (Braun \& Amorim, 2014). The technique began with individual brainstorming by participants to produce a qualitative list of factors and attitudes, to collect participants' perceptions of the conservancy's strengths, weaknesses and opportunities, and any threats (SWOT; Maynard \& Jacobson, 2017). After documenting each individual's perspective, the group shared and discussed each participant's views. Compiled group responses were then ranked from most to least important. The nominal group technique rankings per group resulted in weighted values for ideas discussed, and facilitated a quantitative comparison of perspectives and issues among stakeholders and across communities (Maynard \& Jacobson, 2017); Kurttila et al., 200o; Scolozzi et al., 2014). Similar to the Delphi method, which has been used for engaging community members in conservation planning (e.g. Rust, 2017), ranking ideas with the nominal group technique using each category (strength, weakness, opportunity, threat) indicates practical priorities for community-based natural resource management to address in each conservancy, in addition to specific issues for comparison among stakeholders.
The nominal group technique questions were translated into the Maasai language (Maa), back-translated to English by native Maa speakers (Behling \& Law, 200o), and pilottested twice with two additional stakeholder groups who work in the conservancies: the community women's group and a group of local Maasai researchers. Notes taken in Maa and English were combined and compared with audio recordings of the meetings for verification.

Each group meeting lasted 3-4 hours. A meal was provided, as is customary in Maasai culture, to facilitate the long meeting and the travel required, and to keep participants engaged.

\section{Stakeholder collaboration index analyses}

Qualitative results for each component of the SWOT framework were categorized deductively (Bazeley, 2009) into three ecosystem management themes: ecological, institutional and socio-economic (Meffe, 2002). Ideas were coded into concepts by two researchers and cross-verified for agreement, then coded by category, and assigned to the overarching themes as recommended by Bazeley (2009).

To calculate the stakeholder collaboration index, quantitative frequencies and relationships among the topics listed were identified and ranked (Maynard \& Jacobson, 2017). Responses were analysed by weighting the ranked values (1, highest; 2, second highest; 3, third highest), grouping ranked topics into ecosystem management themes, and taking the sum of weighted ranks of the themes. For sums to represent the amount of support for a given theme, the ranks were reversed. Factors were then sorted from highest to lowest sum of importance. Factors and categories without 
high rankings were given lower priority. To compare the ranked data between stakeholder groups and conservancies we used Fisher's exact test for categorical data, in SPSS v. 23 (IBM, Armonk, USA).

The stakeholder collaboration index was calculated to identify perspectives shared by stakeholders as opportunities for collaborative management, based on the variety and ranking of the ideas shared. The index is used to identify two values for collaboration: the shared perspectives within each stakeholder group, and the amount of overlap between groups in the same conservancy. Greater similarity within a stakeholder group and less variance in respondents' answers leads to higher scores, which indicates higher potential for within-group collaboration. Topics with similar scores in different stakeholder groups represent opportunities to collaborate in a multi-stakeholder management structure.

The stakeholder collaboration index shows the central tendency and dispersion of responses for each stakeholder group on a scale of $0-1$. A score of 1 occurs if all respondents give the same answer, and thus indicates the highest potential for stakeholder collaboration. A score of o indicates all responses are different and there is therefore the least potential for stakeholder collaboration. Bearing in mind the focus on collaboration in this study, the stakeholder collaboration index values were calculated by taking the inverse of the Potential for Conflict Index formula adapted from Vaske et al. (2010). The results are displayed in bubble graphs (Fig. 2; Vaske, 2008). Unlike the traditional focus on dispersion for conflict values, the size of the bubble for the stakeholder collaboration index indicates the relative similarity in perspectives within a group (the larger the bubble, the more within-group potential for stakeholder collaboration), and overlapping bubbles indicate opportunities for betweengroup collaboration.

\section{Results}

The focus groups identified 455 items (115 strengths, 107 weaknesses, 125 opportunities and 108 threats) within the soio-economic, ecological and institutional themes. The socio-economic theme had the highest overall weighted ranking for each of the categories of strengths, weaknesses and opportunities identified by the focus group participants. The ecological theme had the highest rank for the threats category.

\section{Strengths}

The highest-ranked strengths identified by managers and scouts were community land ownership and governance, and community participation in the conservancy, including engagement with and willingness to support the conservancy (Table 1). The stakeholder groups did not differ in their perspectives regarding the three ecosystem management themes (Fisher's exact test, $\mathrm{P}=0.128$ ). Scouts had a high stakeholder collaboration index score (o.82) for institutional topics, suggesting within-group agreement on current successes in the conservancy as an organization. Managers varied more in their responses and rankings (Fig. 2a). The index identified that ecological and socio-economic strengths overlapped in ranking of importance for the managers and scouts, indicating potential between-group agreement.

\section{Weaknesses}

Managers and scouts differed in weakness rankings, except regarding the lack of adequate numbers of scouts (Table 1). The index scores indicated that managers have high within-group potential for stakeholder collaboration on institutional topics (0.90), whereas scouts have the most shared viewpoints on socio-economic weaknesses (0.71; Fig. 2b). Both groups ranked socio-economic weaknesses as being important, as indicated by the between-group overlap for these scores, but differed in their opinions of the importance of ecological and institutional weaknesses (Fig. 2b). Managers ranked institutional weaknesses highly, whereas ecological issues were more important to the scouts (Fisher's exact test, $\mathrm{P}<0.0001$ ).

\section{Opportunities}

Both stakeholder groups assigned high ranking to direct benefits reaching the community, improved conservancy management, and external partnerships with outside organizations and the government as opportunities for the future (Table 1). Stakeholder group rankings of opportunities differed significantly by ecosystem management theme (Fisher's exact test, $\mathrm{P}=0.0036$ ). Managers showed the most within-group potential for collaboration regarding ecological opportunities for the conservancies (0.78), whereas scouts had the most potential for collaboration on institutional topics (0.79; Fig. 2c). Both groups ranked institutional and socio-economic opportunities highly, as indicated by between-group overlap, but managers valued ecological opportunities more than scouts (Fig. 2c).

\section{Threats}

Top threats discussed by managers and scouts did not differ (Fisher's exact test, $\mathrm{P}=0.255$; Fig. 2d, Table 1). Managers had high within-group potential for stakeholder collaboration regarding institutional threats (0.94); there were intermediate levels of potential for collaboration for the other threat categories, and the stakeholders' views overlapped for all ecosystem management themes (Fig. 2d). 
TABLE 1 A ranked list of the top five topics in each strengths, weakness, opportunities and threats category discussed by the direct stakeholders (managers and scouts) of five conservancies in the southern Rift Valley of Kenya (Fig. 1).

\begin{tabular}{|c|c|c|c|}
\hline Topic (by category) & Theme & Managers & Scouts \\
\hline \multicolumn{4}{|l|}{ Strengths } \\
\hline Community land & Socio-economic & 1 & 1 \\
\hline Community participation & Institutional & 2 & 2 \\
\hline Ecological features & Ecological & & 3 \\
\hline Natural resources & Ecological & 3 & \\
\hline Unified community & Socio-economic & & 4 \\
\hline Benefits for community & Socio-economic & 4 & \\
\hline Positive attitudes & Socio-economic & & 5 \\
\hline Culture & Socio-economic & 5 & \\
\hline \multicolumn{4}{|l|}{ Weaknesses } \\
\hline Need more scouts & Institutional & 1 & 1 \\
\hline Problems marketing & Institutional & 2 & \\
\hline Disunity in community & Socio-economic & & 2 \\
\hline Political conflicts & Socio-economic & 3 & \\
\hline Scouts lack equipment & Institutional & & 3 \\
\hline $\begin{array}{l}\text { Lack of management } \\
\text { capacity }\end{array}$ & Institutional & 4 & \\
\hline Lack of education & Socio-economic & & 4 \\
\hline Poor management & Institutional & 5 & \\
\hline Land subdivision & Socio-economic & & 5 \\
\hline \multicolumn{4}{|l|}{ Opportunities } \\
\hline Benefits for community & Socio-economic & 1 & 1 \\
\hline Management & Institutional & 2 & 2 \\
\hline Partnerships & Institutional & 3 & 3 \\
\hline Community participation & Institutional & 4 & \\
\hline Unified community & Socio-economic & & 4 \\
\hline Culture & Socio-economic & 5 & \\
\hline More scouts & Institutional & & 5 \\
\hline \multicolumn{4}{|l|}{ Threats } \\
\hline Human-wildlife conflict & Ecological & 1 & 1 \\
\hline Poaching & Ecological & 2 & 2 \\
\hline No compensation & Socio-economic & 3 & 3 \\
\hline Lack of benefits & Socio-economic & 4 & 4 \\
\hline Ecological features & Ecological & 5 & \\
\hline Land subdivision & Ecological & & 5 \\
\hline
\end{tabular}

\section{Discussion}

Efforts to improve collaboration focus on interactions among actors; community-based programmes depend on positive, reciprocal relationships to facilitate successful conservancies (Margerum, 2008). Diverse members and clear governance structures promote successful collaborative natural resource partnerships (Bonnell \& Koontz, 2007; Rinkus et al., 2016). However, researchers have found there is widespread confusion about community-based natural resource management programmes within communities (Musumali et al., 2007), thus increased stakeholder engagement and communication is vital. Our emphasis on the stakeholder collaboration index highlights opportunities for participatory processes by promoting inclusion, power-sharing and joint decision-making (Berkes, 2010). Our study expands (a) Strengths

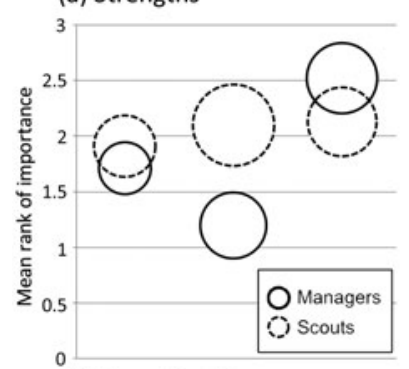

(c) Opportunities

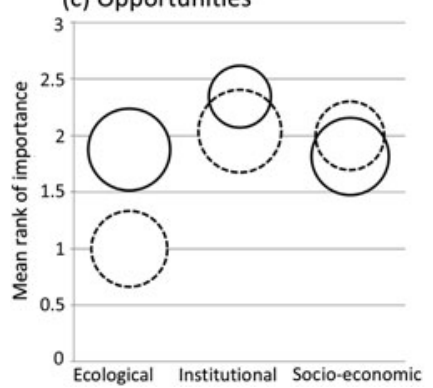

(b) Weaknesses

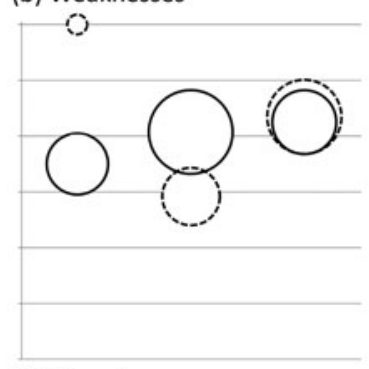

(d) Threats

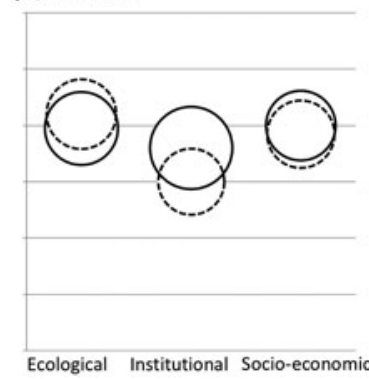

FIG. 2 Stakeholder collaboration index comparing the mean importance scores of two stakeholder groups in their analyses of the (a) strengths, (b) weaknesses, (c) opportunities, and (d) threats they perceived for their conservancies (Fig. 1), for three ecosystem management themes. The centre point of each bubble represents the scale mean. Bubble size reflects the stakeholder collaboration index score, with larger bubbles indicating greater similarities within a stakeholder group and less variance in respondents' answers, and thus higher potential for within-group collaboration. Overlapping bubbles indicate greater potential for between-group collaboration. The scale on the $y$-axis measures the level of importance of the issues, ranked by the participants from o (no importance) to 3 (highly important).

conventional evaluation techniques used for environmental management and natural resource governance (Lozano \& Vallés, 2007; Nikolaou \& Evangelinos, 2010; Martins et al., 2013). The stakeholder collaboration index used with the ranking capability of the nominal group technique provided a framework for potentially improving collaborative management by identifying factors with immediate collective agreement as a focus for future collaborative interventions.

The analysis provided broad results applicable to community-based natural resource management. It identified common issues between stakeholders as a basis for encouraging collaboration. By integrating the stakeholder collaboration index into conservancy evaluation, new types of data could be measured; i.e. stakeholder perceptions and objectives of community-based natural resource management programmes. Additionally, although the index was used here with nominal group technique data ranked by groups, it is also applicable to traditional survey data with a symmetrical response scale (Vaske, 2008).

Based on the results, we identified two values for collaboration relevant to community-based natural resource 
management programmes: the stakeholder collaboration index scores within each stakeholder group and the degree of overlap between groups in the same conservancy (Fig. 2). Several of the ecosystem management themes had intermediate to high within-group scores for both groups of stakeholders. For example, the managers' high within-group collaboration score for perceived institutional threats and the scouts' high within-group score for institutional opportunities indicated the groups have strong agreement and could work together to address challenges. The betweengroup comparisons identified shared perspectives of the two stakeholder groups. For example, strongly overlapping views regarding threats indicated potential for collaboration between the managers and scouts to strategically address future challenges in the ecological, institutional and socioeconomic areas of the conservancies.

Visualization of the within- and between-group overlap in the collaboration index facilitates assimilation of the findings for application in management (Manfredo et al., 2003). The index refocuses the lens used to assess stakeholders on shared perspectives rather than on conflicting views. In contrast, using the Potential for Conflict Index, Vaske \& Taylor (2006) identified subjects to avoid regarding wolf management in Wyoming, and Engel et al. (2017) assessed variations in perceptions of the acceptability of killing big cats. The Potential for Conflict model (Manfredo et al., 2003) identified areas in which conflict could be minimized but did not result in recommended steps for engaging the participants in collaborative conservation. The stakeholder collaboration index eliminates this problem, with findings that support decision-making for effective environmental management.

In our study, managers and scouts differed in their descriptions of current weaknesses and future opportunities, whereas they shared similar perspectives on the strengths of their conservancies, and future threats. Earlier studies using the Potential for Conflict Index to assess stakeholder perceptions of wildlife management agencies and hunting regulations found that the most important factor that influenced perception was participants' specific beliefs about a topic, and not their demographic background or prior experience (Donnelly \& Vaske, 1995). Using the stakeholder collaboration index, the beliefs represented in the similarly ranked institutional and socio-economic issues could be the focus for collaborative discussions in the conservancies. Similar issues ranked highly by both groups included community unification and participation within the conservancy, as well as improved partnerships and increased benefits and management capacity. These findings provide many potential focal points for collaborative management discussions and decision-making among stakeholders.

When the stakeholders' perspectives differed, their differences were related to their distinct involvement in the conservancies. Managers oversee the institution, whereas scouts implement and enforce rules; institutional strengths were ranked more highly by scouts, who operate the conservancies on a daily basis, yet the scouts shared concerns about the community-based natural resources programme, such as the lack of adequate scout numbers and necessary equipment. Also, scouts perceived ecological weaknesses as being more important because they witness environmental problems such as land degradation and poaching. In contrast, managers were focused on institutional characteristics and economic improvements. For example, managers ranked institutional weaknesses as high, demonstrating high potential for within-group collaboration. The managers could use their consensus to strategize their next steps for conservation management, while also looking to the scouts, to incorporate their concerns.

Although perceptions of future opportunities often differed between managers and scouts, there was overlap among several of the highest ranked opportunities regarding direct benefits to the communities. Both groups desired increased economic revenue, tourism employment, and school scholarships. Community-based wildlife conservation projects are strengthened when local communities have access to benefits from wildlife (Mburu \& Birner, 2007). However, sometimes benefits reach elites rather than the community overall, and as a result local people's livelihoods, as well as their support for conservation, can be diminished (Sachedina \& Nelson, 2010; Warren \& Visser, 2016). Based on the participants' shared views of a lack of clear benefits, we recommend that transparent and organized benefit distribution be implemented to support broader community engagement and tolerance of the costs of living with wildlife.

To promote effective, participatory community-based natural resource management, matters that the various stakeholders agree on could be addressed first, to establish collaboration within project management. After setting up participatory decision-making structures by addressing shared perspectives, topics with more conflicting perspectives could be addressed. Ongoing evaluation of stakeholder interactions using tools such as the stakeholder collaboration index can support partnership effectiveness (Rinkus et al., 2016).

The stakeholder collaboration index provides a rapid method for understanding and prioritizing potential solutions to problems in community-based natural resource management. In this study, applying the index to stakeholder engagement supported the identification of shared perspectives for fostering the development of critical, participatory structures for collaborative management. Community-based managers could use the index with diverse stakeholder groups to promote transparency and increase collaboration in management, cultivating community participation in conservation practices and creating the capacity to address future challenges. In Kenya, 
evaluation with the stakeholder collaboration index clarified the conservancies' strengths and weaknesses and the stakeholders' goals for community-based natural resource management. Future research could also incorporate external stakeholders to assess the efficacy of this framework in identifying community management issues from the perspectives of all relevant stakeholders, and to support the implementation of truly participatory policies for collaborative management.

Acknowledgements We are grateful to the communities in the southern Rift Valley of Kenya for their hospitality and for teaching us about their conservancies; the South Rift Association of Land Owners; Samantha du Toit, Peter Tajeu, Sanguet Pelo and the research team at Lale'enok Resource Centre for research support; M. Monroe and B. Child for their helpful review of the study methods and analysis; and M. Kinnaird and J. Hardesty for their review of the text. The University of Florida Tropical Conservation and Development Program, the Angel Fund, the Vogel Trust, and Rendigs, Fry, Kiely \& Dennis provided financial support.

Author contributions Study design and implementation, fundraising, data analysis, and writing: LM; advice on development of ideas, project oversight, help with fundraising, editing and oversight: SKJ; project guidance, participant recruitment, editing: JK.

\section{Conflicts of interest None.}

Ethical standards This research abided by the relevant ethical guidelines, including Institutional Review Board approval from the University of Florida and adherence to the legal requirements of Kenya.

\section{References}

Bazeley, P. (2009) Analysing qualitative data: more than 'identifying themes'. The Malaysian Journal of Qualitative Research, 2, 6-22.

BeHLing, O. \& LAw, K.S. (eds) (200o) Translating Questionnaires and Other Research Instruments: Problems and Solutions, Vol. 133. Sage, New York, USA.

BERKES, F. (2004) Rethinking community-based conservation. Conservation Biology, 18, 621-630.

Berkes, F. (2007) Adaptive co-management and complexity: exploring the many faces of co-management. In Adaptive Co-Management: Collaboration, Learning and Multi-Level Governance (eds D.R. Armitage, F. Berkes \& N.C. Doubleday), pp. 19-38. UBC Press, Vancouver, Canada.

BERKES, F. (2010) Devolution of environment and resources governance: trends and future. Environmental Conservation, 37, 489-500.

Bonnell, J. \& Koontz, T. (2007) Stumbling forward: the organizational challenges of building and sustaining collaborative watershed management. Society \& Natural Resources, 20, 153-167.

Braun, R. \& Amorim, A. (2014) Rapid 'SWOT' diagnosis method for conservation areas. Scottish Geographical Journal, 131, 17-35.

Brooks, J.S., Waylen, K.A. \& Borgerhoff-Mulder, M. (2012) How national context, project design, and local community characteristics influence success in community-based conservation projects. Proceedings of the National Academy of Sciences of the United States of America, 109, 21265-21270.
Donnelly, M.P. \& VAske, J.J. (1995) Predicting attitudes toward a proposed moose hunt. Society \& Natural Resources, 8, 307-319.

Engel, M.T., Vaske, J.J., Bath, A.J. \& Marchini, S. (2017) Attitudes toward jaguars and pumas and the acceptability of killing big cats in the Brazilian Atlantic Forest: an application of the Potential for Conflict Index $x_{2}$. Ambio, 46, 604-612.

Folke, C., Hahn, T., Olsson, P. \& Norberg, J. (2005) Adaptive governance of social-ecological systems. Annual Review Environment and Resources, 30, 441-473.

Horwich, R.H. \& Lyon, J. (2007) Community conservation: practitioners' answer to critics. Oryx, 41, 376-385.

Jehn, K.A. \& Mannix, E.A. (2001) The dynamic nature of conflict: a longitudinal study of intragroup conflict and group performance. Academy of Management Journal, 44, 238-251.

Keough, H.L. \& Blahna, D.J. (2006) Achieving integrative, collaborative ecosystem management. Conservation Biology, 20, 1373-1382.

Konisky, D.M. \& Beierle, T.C. (2000) Values, conflict, and trust in participatory environmental planning. Journal of Policy Analysis and Management, 19, 587-602.

Kurttila, M., Pesonen, M., Kangas, J. \& Kajanus, M. (2000) Utilizing the analytic hierarchy process (AHP) in SWOT analysisa hybrid method and its application to a forest-certification case. Forest Policy and Economics, 1, 41-52.

Larson, L.R., Conway, A.L., Krafte, K.E., Hernandez, S.M. \& CARROLL, J.P. (2016) Community-based conservation as a potential source of conflict around a protected area in Sierra Leone. Environmental Conservation, 43, 242-252.

Lozano, M. \& VAlLés, J. (2007) An analysis of the implementation of an environmental management system in a local public administration. Journal of Environmental Management, 82, 495-511.

Madden, F. \& McQuinn, B. (2014) Conservation's blind spot: the case for conflict transformation in wildlife conservation. Biological Conservation, 178, 97-106.

McDougall, C. \& BAnjade, M.R. (2015) Social capital, conflict, and adaptive collaborative governance: exploring the dialectic. Ecology and Society, 20, 44.

Manfredo, M.J. (2008) Who Cares About Wildlife? Springer, New York, USA.

Manfredo, M.J., Vaske, J.J. \& Teel, T.L. (2003) The Potential for Conflict Index: a graphic approach to practical significance of human dimensions research. Human Dimensions of Wildlife, 8 , 219-228.

Margerum, R.D. (2008) A typology of collaboration efforts in environmental management. Environmental Management, 41, 487-500.

Margoluis, R., Stem, C., Salafsky, N. \& Brown, M. (2009) Design alternatives for evaluating the impact of conservation projects. New Directions for Evaluation. Special Issue: Environmental Program and Policy Evaluation: Addressing Methodological Challenges, 85-96.

Martins, G., Brito, A. G., Nogueria, R., Urena, M., Fernandex, D., Luque, F. J. \& Alcacer, C. (2013). Water resources management in southern Europe: clues for a research and innovation based regional hypercluster. Environmental Management, 119, 76-84.

Masozera, M.K., Alavalapati, J.R.R., Jacobson, S.K. \& Shrestha, R.K. (2006) Assessing the suitability of community-based management for the Nyungwe Forest Reserve, Rwanda. Forest Policy and Economics, 8, 206-216.

MAYNARD, L. \& JACOBSON, S.K. (2017) Stakeholder participation in wildlife management: adapting the nominal group technique in developing countries for participants with low literacy. Human Dimensions of Wildlife, 22, 71-82. 
Mburu, J. \& Birner, R. (2007) Emergence, adoption, and implementation of collaborative wildlife management or wildlife partnerships in Kenya: a look at conditions for success. Society \& Natural Resources, 20, 379-395.

Meffe, G.K. (2002) Ecosystem Management: Adaptive, CommunityBased Conservation. Island Press, Washington, DC, USA.

Mushove, P. \& Vogel, C. (2005) Heads or tails? Stakeholder analysis as a tool for conservation area management. Global Environmental Change, 15, 184-198.

Musumali, M.M., Larsen, T.S. \& Kaltenborn, B.P. (2007) An impasse in community based natural resource management implementation: the case of Zambia and Botswana. Oryx, 41, 306-313.

Nikolaou, I.E. \& Evangelinos, K.I. (2010) A SWOT analysis of environmental management practices in Greek mining and mineral industry. Resources Policy, 35, 226-234.

REED, M.S. (2008) Stakeholder participation for environmental management: a literature review. Biological Conservation, 141, 2417-2431.

Rinkus, M.A., Dobson, T., Gore, M.L. \& Dreelin, E.A. (2016) Collaboration as process: a case study of Michigan's watershed permit. Water Policy, 18, 182-196.

RUst, N.A. (2017) Can stakeholders agree on how to reduce humancarnivore conflict on Namibian livestock farms? A novel Q-methodology and Delphi exercise. Oryx, 51, 339-346.

Sachedina, H. \& Nelson, F. (2010) Protected areas and community incentives in savannah ecosystems: a case study of Tanzania's Maasai Steppe. Oryx, 44, 390-398.

Saengsupavanich, C., Gallardo, W.G., Sajor, E. \& Murray, W.W. (2012) Constraints influencing stakeholder participation in collective environmental management. Environmental Earth Sciences, 66, 1817-1829.

Scolozzi, R., Schirpke, U., Morri, E., D’Amato, D. \& Santolini, R. (2014) Ecosystem services-based SWOT analysis of protected areas for conservation strategies. Journal of Environmental Management, 146, 543-551.

Thompson, J.R., Elmendorf, W.F., McDonough, M.H. \& Burban, L.L. (2005) Participation and conflict: lessons learned from community forestry. Journal of Forestry, 103, 174-178.

TullberG, J. (2013) Stakeholder theory: some revisionist suggestions. The Journal of Socio-Economics, 42, 127-135.
Van de Ven, A.H. \& DelbecQ, A.L. (1971) Nominal versus interacting group processes for committee decision-making effectiveness. Academy of Management Journal, 14, 203-212.

VAske, J.J. (2008) Survey Research and Analysis: Applications in Parks, Recreation and Human Dimensions. Venture Publishing, State College, USA.

VASKe, J.J. \& TAYLOR, J.G. (2006) Visitor and resident acceptability norms towards wolf management actions. In Exploring the Nature of Management. Proceedings of the Third International Conference on Monitoring and Management of Visitor Flows in Recreational and Protected Areas (eds D. Siegrist, C. Clivaz, M. Hunziker \& S. Iten), pp. 409-410. University of Applied Sciences, Rapperswil, Switzerland.

Vaske, J.J., Needham, M.D., Newman, P., Manfredo, M.J. \& Petchenik, J. (2006) Potential for conflict index: hunters' responses to chronic wasting disease. Wildlife Society Bulletin, 34, 44-50.

Vaske, J.J., Beaman, J., Barreto, H. \& Shelby, L.B. (2010) An extension and further validation of the Potential for Conflict Index. Leisure Sciences, 32, 240-254.

Wald, D.M., Jacobson, S.K. \& Levy, J.K. (2013) Outdoor cats: identifying differences between stakeholder beliefs, perceived impacts, risk and management. Biological Conservation, 167, 414-424.

Wall, J.A. \& Callister, R.R. (1995) Conflict and its management. Journal of Management, 21, 515-558.

WARREN, C. \& Visser, L. (2016) The local turn: an introductory essay revisiting leadership, elite capture and good governance in Indonesian conservation and development programs. Human Ecology, 44, 277-286.

Western, D., Russell, S. \& Cuthill, I. (2009) The status of wildlife in protected areas compared to non-protected areas of Kenya. PLOS ONE, 4, e6140.

Western, D., Waithaka, J. \& Kamanga, J. (2015) Finding space for wildlife beyond national parks and reducing conflict through community-based conservation: the Kenya experience. Parks, 21, 51-62.

Wondolleck, J.M. \& Yaffee, S.L. (2000) Making Collaboration Work: Lessons From Innovation in Natural Resource Management. Island Press, Washington, DC, USA. 